\title{
Application of Various Equations for Estimating GFR in Patients with Type 1 Diabetes
}

\author{
M. V. Kaplanian ${ }^{1, ~}$, A. B. Hodzhayan ${ }^{1}$, M. G. Gevandova ${ }^{1}$, K. S. Elbekyan ${ }^{1}$, E. V. Kaplanova ${ }^{2}$, \\ K. R. Amlaev ${ }^{1}$
}

${ }^{1}$ Stavropol State Medical University of Russian Ministry of Health, Stavropol, Russian Federation

${ }^{2}$ Kuban State University, Krasnodar, Russian Federation

Email address:

mayram777@rambler.ru (M. V. Kaplanian), postmaster@stgmu.ru (M. V. Kaplanian), evkaplanova@mail.ru (E. V. Kaplanova)

${ }^{*}$ Corresponding author

\section{To cite this article:}

M. V. Kaplanian, A. B. Hodzhayan, M. G. Gevandova, K. S. Elbekyan, E. V. Kaplanova, K. R. Amlaev. Application of Various Equations for Estimating GFR in Patients with Type 1 Diabetes. American Journal of Internal Medicine. Vol. 8, No. 2, 2020, pp. 73-77. doi: 10.11648/j.ajim.20200802.15

Received: April 12, 2019; Accepted: June 23, 2019; Published: March 17, 2020

\begin{abstract}
To compare different methods of estimating glomerular filtration rate (GFR) calculated by creatinine and cystatin $\mathrm{C}$ in patients with type 1 diabetes with normal and moderately decreased renal filtration function. The study involved 57 patients with type 1 diabetes, 37 men and 20 women, aged from 21 to 57 years (median 30 years), with disease duration after diagnosis from 33 to 2 years (median 8 years). The control group comprised 15 non-diabetic people aged 19 to 42 years (median - 28 years), with normal levels of albuminuria and blood creatinine. The majority of patients with type 1 diabetes were found to have decompensated diabetes mellitus. The mean value of glycated hemoglobin in patients was $8 \%$. The renal glomerular function was estimated by level of GFR and triple testing of urine albumin excretion. Renal tubular function in type 1 diabetes was tested by examining serum cystatin C. GFR estimating equations, which did not include serum of cystatin $\mathrm{C}$ produced higher GFR. As a result, the majority of patients had normal or elevated GFR showing hyperfiltration. Using cystatin-C-based equations resulted in a several-fold reduction in the number of patients with hyperfiltration and increased number of cases with GFR below $90 \mathrm{ml} / \mathrm{min} / \mathrm{m}^{2}$. The assessment of the relationship between SDMA and GFR showed negative correlation with both cystatin-C-based and creatinine-based equations. These findings revealed that GFR estimating equations based on both creatinine and cystatin $\mathrm{C}$ produce more accurate results compared with the reference estimating equations.
\end{abstract}

Keywords: Diabetic Nephropathy, Type 1 Diabetes, Cystatin C, Symmetric Dimethylarginine

\section{Introduction}

Diabetic nephropathy (DN) and the terminal stage of chronic kidney failure resulting from it are among the most common reasons of death in patients with type 1 diabetes (T1DM). Its complicated pathogenesis, long-lasting asymptomatic progression, and late diagnostics all contribute to the poor efficacy of DN pathogenic therapy. The results of epidemiological screening in different Russian regions show that the actual prevalence of DN 2-4 times exceeds the factual [1]. The functional and structural changes of kidneys develop throughout the first 5 years from the onset of diabetes. The earliest morphological signs of nephropathy include a hypertrophy of glomeruli, a proliferation of mesangial cells, and a thickening of capillary loop wall; they are followed by the development of dystrophic and atrophic changes of tubules, fibrosis, arterial and arteriolar interstice [2-3].

An increase in urine albumin excretion does not always indicate an unfavorable prognosis for the kidney function, moreover, such a condition proves to be reversible, and at the same time there are samplings of patients with a progressive decrease in GFR without the concomitant increase in urine albumin excretion. In their longitudinal observation of DN patients after pancreatic transplantation Fioretto et al. showed that patients with type 1 diabetes had a regression of structural changes of kidney tissue, ten years after the full 
elimination of hyperglycemia (T1DM). [4-6] A stable normalization of carbohydrate metabolism, as well as a timely prescription of therapy for arresting intraglomerular hypertension can stop the pathological kidney process at early stages. So the problem of ongoing search for early criteria of kidney damage in diabetic patients remains highly relevant. And what is meant by early diagnostics of DN? Is an increase in urine albumin excretion (UAE) of more than $300 \mathrm{mg} /$ day considered a timely diagnosis of DN? Indeed, the increase of UAE within $30-300 \mathrm{mg} /$ day is a prodrome of the development of DN clinically full-scale stage. The urine albumin excretion of healthy people is on average 6,5 $\mathrm{mcg} /$ day. [7]. It should be noticed that diagnosticating of "high normal" UAE in DM patients is a predictor of microalbuminuria development [8, 9]. Daily range of albumin excretion rate of both healthy people and DM patients is $40-45 \%$ [10]. The findings of long observations show that microalbuminuria considerably raises the risk of cardiovascular accidents and cardiovascular pathology death among DM2 patients [11-12]. Microalbuminuria is also associated with cardiorenal mortality in T1DM [13]. According to Finn Diane study results (Finnish Diabetic Nephropathy study), having microalbuminuria is connected with the increase in T1DM patients' common mortality by 2,8 times [14]. Exact correlation of microalbuminuria in the development of unfavorable prognosis is explained by its close connection with other risk factors for cardiovascular pathology [15]. Serum level of endogenous creatinine is the main determinant of GFR value. The principle disadvantage of GFR estimating equations is the difficulty of its validization with those people whose creatinine level can differ from average numbers (due to the muscle bulk, the degree of physical activity). According to the researches DM patients have low creatinine serum level, which is explained by reduced absolute (or relative against obesity) muscle mass [9, 12]. Hyperglycemia leads to hyperphiltration development that complicates evaluation of functional nephrons' state [16]. Attempts of using alternative markers of kidney function estimation are made with regard for disadvantages of using creatinine for GFR evaluation. As a reflection of this process there appear methods of GFR evaluation on the basis of cystatin $\mathrm{C}$. Cystatin $\mathrm{C}$-is a nonglycosylated protein belonging to the second group of cystatin genetic family. It was first distinguished as a cerebrospinal fluid protein and urinary protein in people with kidney pathology [17]. Cystatin synthesis is carried out by all nuclear cells of body at constant rate depending on kidney function. According to comparative study results, clarification of the dependence of cystatin $\mathrm{C}$ serum level on the GFR values allowed putting GFR evaluation formula in clinical practice [16]. Single measurement of cystatin C serum level enables us to calculate GFR more accurately in the comparison with the endogenous creatinine level [17, 19]. There are also findings indicating that the sensibility of urinary cystatin $\mathrm{C}$ test method reaches $70 \%$ after the second year of T1DM in children [18].

Several works about the research of cystatin $\mathrm{C}$ in diabetic nephropathy have been published [16], but its role in complex examination of kidney function in T1DM patients remains understudied. There are faults in using of cystatin $\mathrm{C}$ as a marker of renal dysfunction. So its increase can be associated with age, male gender, fat mass, triglyceride and uric acid concentration, arterial hypertension, DM [16-19].

It is stated that the increase of symmetric dimethylarginine serum level is a mechanism of the development of bloodstream pathological changes in case of chronic kidney disease [20, 21]. Symmetric dimethylarginine (SDMA) is a methylated derivative of L-arginine amine acid. It is produced mainly by kidneys; its plasma level reflects renal function. Meta-analysis of 18 researches with 2136 participating patients showed negative relation between SDMA concentration and reference GFR estimating equations according to inulin clearance $[22,23]$. Adults and children with early stages of kidney failure have increased SDMA negatively correlating with GFR [24].

The aim of the research: the comparison of different methods of estimating GFR calculated by creatinine and cystatin $\mathrm{C}$ in T1DM patients with normal and moderately decreased renal filtration function.

\section{Material and Methods}

The study involved 57 patients with T1DM, 37 men and 20 women aged from 21 to 57 years (median-30 years), with disease duration after diagnosis from 33 to 2 years (median 8 years). GFR values calculated by using GFR-EPIcreat were within normal reference range or moderately decreased (60$89 \mathrm{ml} / \mathrm{min} / 1,73 \mathrm{~m}^{2}$ ). All the patients underwent common clinical examination, laboratory evaluation of kidney functional state and the control of compensation of carbohydrate metabolism were also carried out. The majority of patients with T1DM were found to have decompensated carbohydrate metabolism (according to glycosylated hemoglobin level) regardless of the disease duration. The mean values of glycosylated hemoglobin in patients were $8 \%$. The control group comprised 15 non-diabetic people aged from 19 to 42 years (median -28 years) with normal levels of albuminuria and blood creatinine. All the patients included in the study got insulin therapy in basal-bolus regimen. All of the examined patients had no arterial hypertension, and they didn't get angiotensin converting enzyme inhibitor or angiotensin II receptor antagonists with a nephroprotective aim. The study didn't involve non-diabetic patients with primary kidney pathology, patients with urinary tract infections, nephrotic syndrome, chronic kidney disease (CKD) of stages 2-5, chronic inflammatory disease.

According to the recommendations of KDIGO experts on diagnosis and treatment of CKD, GFR was calculated by CKD-EPI formulas on the basis of serum creatinine (CKDEPIcreat, 2009) and serum cystatin C (CKD-EPIcys, 2012). Evaluation of serum cystatin $\mathrm{C}$ concentration was made by immunoturbidimetric method with the use of Abbot Architect c8000 analyzer with Human Cystatin C Elisa kits (BioVendor). GFR values were calculated with a calculator 
of the National Kidney Foundation of the USA (http://www.kidney.org/professionals/kdoqi/gfr_calculator.cf $\mathrm{m})$. The control group comprised 15 non-diabetic people aged from 19 to 42 years (median -28 years) with normal levels of albuminuria and blood creatinine. The study protocol is approved by the local ethics committee. Every patient gave written informed consent for participation in the research study.

The statistical analysis was made with the use of STATISTICA 10 program (StatSoft, Inc, 2011, USA) and non-parametric statistics methods. Intergroup differences were estimated with the use of Mann Whitney U-test and Kruskal-Wallis ANOVA test. The interrelation of characteristics was studied with the use of Spearman rank correlation analysis. We took logarithms of variables with the disposal different from normal one, before including them into multifactor models. During testing of statistic hypothesis, the critical level of significance was taken equal to 0,05 .

\section{Results}

GFR evaluation results, received by different methods, showed that CKD-EPI had a positive correlation with GFR estimated by MDRD and Cockroft-Gault formula. At the same time the relationship between CKD-EPI and GFR calculated on the basis of cystatin $\mathrm{C}$ formula wasn't found out. A special place was taken by the formula, which included both creatinine and cystatin C. GFR received on the basis of this formula accurately correlated with GFR by CKD-EPIcreat as well as by CKD-EPI cys (refer to the picture). While further analysis we divided GFR evaluation results into 3 groups: below 90, $90-120$ and above 120 $\mathrm{ml} / \mathrm{min} / \mathrm{m}^{2}$. GFR estimating equations which didn't include serum level of cystatin $\mathrm{C}$ produced higher GFR results (Figure 1). As a result, the majority of patients had normal or elevated GFR showing hyperfiltration. Using cystatin C based equations resulted in a several-fold reduction in the number of patients with hyperfiltration and increased number of cases with GFR below $90 \mathrm{ml} / \mathrm{min} / \mathrm{m}^{2}$ (Figures 2, 3).

As an additional criterion of kidney function evaluation we chose one of the endothelium dysfunction marker symmetric dimethylarginin (SDMA). The measurement range of the marker corresponds to $0,39-0,69 \mathrm{nM} / 1$ (Figure 4). While estimating the relationship between SDMA and GFR, there wasn't found any significant correlation with the evaluation results by Cockroft-Gault formula and MDRD; there was found a very weak relationship with CKD-EPIcreat and CKD-EPIcys, and also a moderate negative correlation with the formula including both cystatin $\mathrm{C}$ and creatinin.

\section{Discussion}

The problem of the diagnosis of early DN manifestations remains unsolved. In our work by preclinical diagnosis we mean those variations of kidney damage when the patient doesn't have manifestations of traditional DN criteria yet, such as higher urine albumin excretion and decreased GFR. To estimate the kidney function we chose the patients who didn't have other reasons for nephropathy but DM, and having normal arterial pressure. The first-time evaluation of kidney function was made on the basis of CKD-EPI formula. The mean value of GFR in this sample was $116,9 \pm 20,71$ $\mathrm{ml} / \mathrm{min}$, and $39 \%$ had GFR above $120 \mathrm{ml} / \mathrm{min} / \mathrm{m}^{2}$, which showed a big part of patients with hyperfiltration. At the same time the negative relationship of creatinin with glucosylated hemoglobin as well as high numbers of glucosylated hemoglobin in the group of patients with GFR above $120 \mathrm{ml} / \mathrm{min} / \mathrm{m}^{2}$ indirectly attested to hyperfiltration affected by decompensated carbohydrate metabolism. The patients of the chosen group had no findings for kidney function damage, and normal values of creatinine, cystatin $\mathrm{C}$ and SDMA confirmed it. Taking into account the aim of study we estimated GFR using other formulas the principal difference of which consisted in using or not using values of serum cystatin $\mathrm{C}$.

GFR estimating equations on the basis of cystatin $\mathrm{C}$ led to the results showing decrease of kidney function in the same sample of the patients, at that not only the mean values changed, but also the part of the patients with GFR below $90 \mathrm{ml} / \mathrm{min} / \mathrm{m}^{2}$ greatly increased. It wasn't unexpected because similar results concerning DN patients had been reported in other works too. Probably, one of the main factors influencing such a result is the development of sarcopenia in DM patients, and consequently lower creatinine synthesis. From clinical positions the received difference between various methods of GFR evaluations in one and the same patient, as it's seen from our work, can have significant meaning. In addition, the range of GFR values could vary from hyperfiltration to decrease of GFR below $90 \mathrm{ml} / \mathrm{min} / \mathrm{m}^{2}$. Available literature findings show that the formula combining creatinine and cystatin $\mathrm{C}$, gives more accurate results compared with the reference estimating equations. In our work we can't compare the received findings with "direct" methods of GFR evaluation, though we can judge indirectly that indeed this variant is more sensible to GFR changes. We can make such a conclusion because of indirect estimation of the negative relationship between GFR and SDMA.

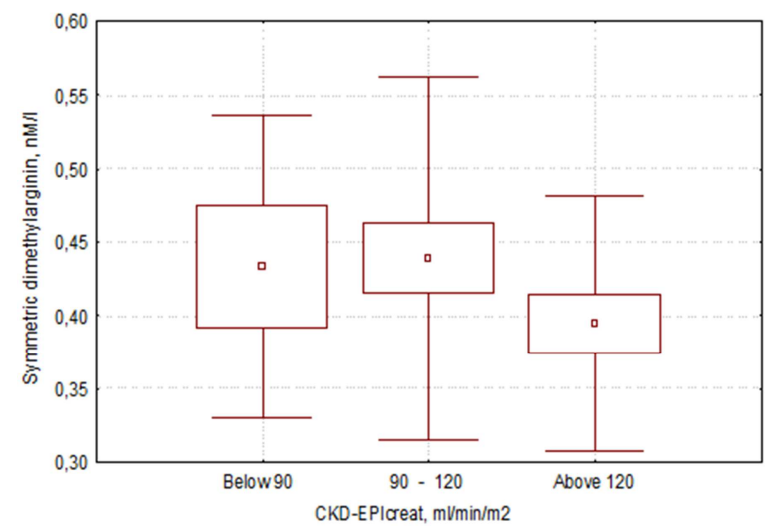

Figure 1. The association between the serum level of symmetric dimethylarginin and GFR creatinin in type 1 diabetes. 


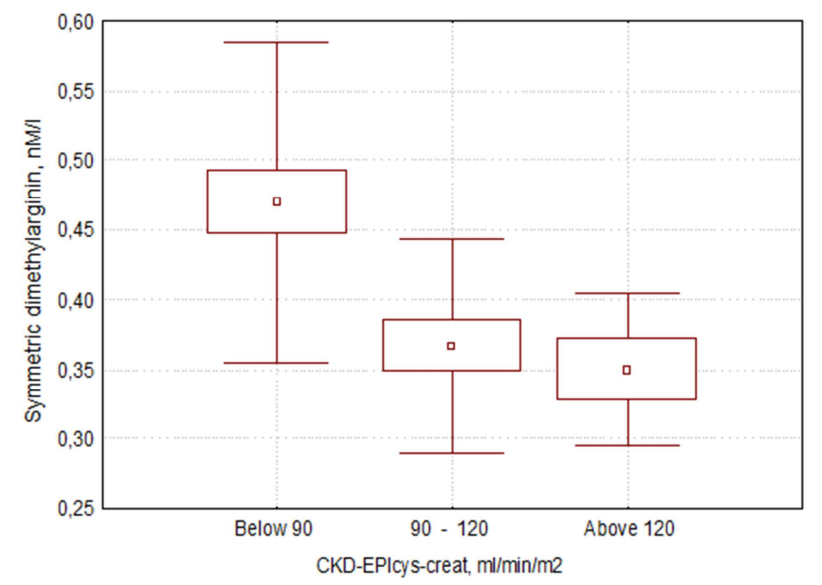

Figure 2. The association between the serum level of symmetric dimethylarginin and GFR creatinin and cystatin $C$ in type 1 diabetes.

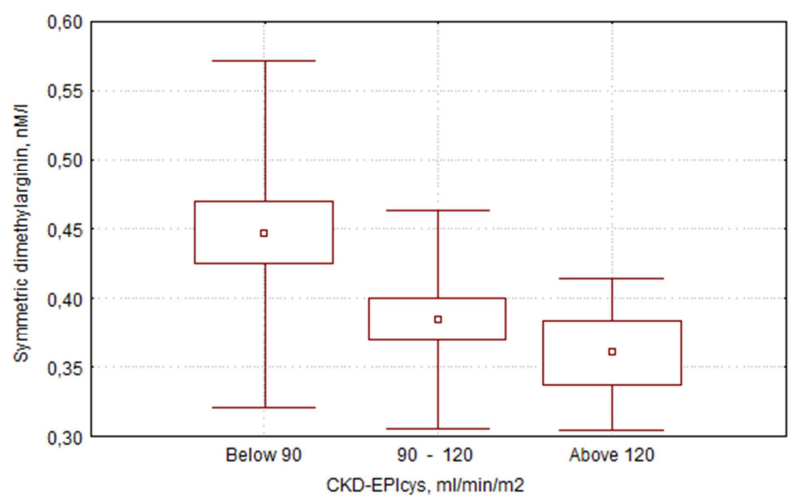

Figure 3. The association between the serum level of symmetric dimethylarginin and GFR cystatin $C$ in type 1 diabetes.

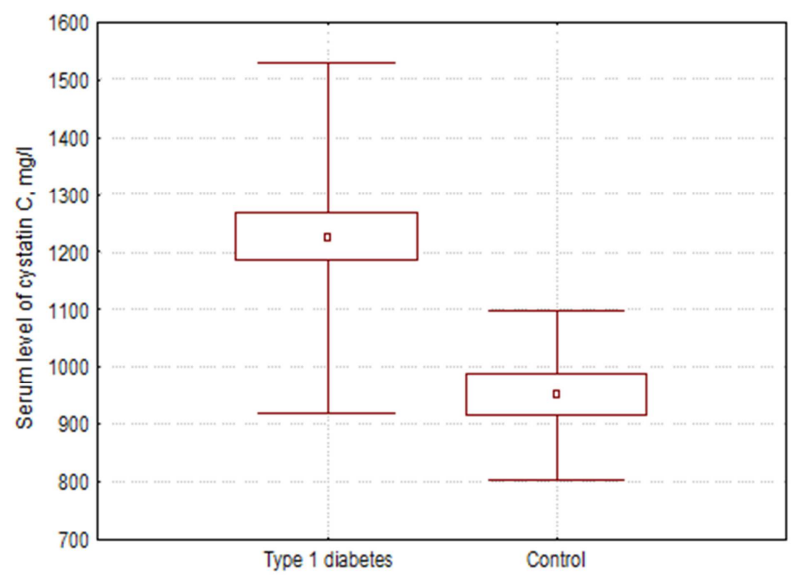

Figure 4. The serum level of symmetric dimethylarginin in type 1 diabetes.

\section{Conclusion}

The use of GFR estimating equations in clinical practice is a certain compromise that let us screen patients with relatively low expenses and enables us to carry out dynamic observation of patients in future to prevent the development of DN. The extent of their accuracy will always be the subject of disputes and research studies, because the question of validization in view of racial, genetic, comorbid and other criteria isn't completely determined.

\section{References}

[1] Dedov, I. I., Vikulova, OK, Sukhareva, O. Yu. Screening for diabetic nephropathy in the Russian Federation. In: Shestakova M. V., Dedov I. I. (Ed.) Diabetes mellitus and chronic kidney disease. M., 2009. P. 39-59.

[2] Fioretto P., Caramori M. L., Mauer M. The kidneys in diabetes: dynamic pathways of injury and repair. The Camillo Golgi Lecture 2007. Diabetologia. 2008; 51: 1051-1057.

[3] Bondar I. A., Klimontov V. V. Functional morphology of the kidneys in diabetes mellitus. In the book: Shestakova M. V., Dedov II, ed. Diabetes mellitus and chronic kidney disease. M., 2009. p. 149-176.

[4] Fioretto P., Sutherland D. E., Najafian B. et al. Remodeling of renal interstitial and tubular lesions in pancreas transplant recipients. Kidney Int. 2006; 69: 907-912.

[5] Viberti G. C., Wiseman M. J. The kidney in diabetes: significance of the early abnormalities. Clin. Endocrinol. Metab. 1986; 15: 753-782.

[6] Microalbuminuria Collaborative Study Group. Predictors of the development of microalbuminuria in patients with Type 1 diabetes mellitus: a seven-year prospective study. Diabet. Med. 1999; 16: 918-925.

[7] Stone M. L., Craig M. E., Chan A. K., Lee J. W., Verge C. F., Donaghue K. C. Natural history and risk factors for microalbuminuria in adolescents with type 1 diabetes: a longitudinal study. Diabetes Care 2006; 29: 2072-2077.

[8] Jerums G., Panagiotopoulos S., Maclsaac R. J. Diabetic nephropathy: epidemiology and clinical description. In: Boner G., Cooper M. E., ed. Management of Diabetic Nephropathy. L., N.-Y. 2003. P. 37-60.

[9] Valmadrid C. T., Klein R., Moss S. E., Klein B. E. The risk of cardiovascular disease mortality associated with microalbuminuria and gross proteinuria in persons with olderonset diabetes mellitus. Arch. Intern. Med. 2000; 160: 1093-1100.

[10] Casiglia E., Zanette G., Mazza A., Donadon V., Donada C., Pizziol A., Tikhonoff V., Palatini P., Pessina A. C. Cardiovascular mortality in non- insulin-dependent diabetes mellitus. A controlled study among 683 diabetics and 683 age- and sexmatched normal subjects. Eur. J. Epidemiol. 2000; 16: 677-684.

[11] Torffvit O., Lovestam-Adrian M., Agardh E., Agardh C. D. Nephropathy, but not retinopathy, is associated with the development of heart disease in Type 1 diabetes: a 12-year observation study of 462 patients. Diabet. Med. 2005; 22 (6): 723-729.

[12] Groop P. H., Thomas M. C., Moran J. L., Wadèn J., Thorn L. M., Mäkinen V. P., Rosengård-Bärlund M., Saraheimo M., Hietala K., Heikkilä O., Forsblom C.; FinnDiane Study Group. The presence and severity of chronic kidney disease predicts all-cause mortality in type 1 diabetes. Diabetes. 2009; 58: 1651-1658.

[13] Mukhin N. A., Fomin V. V., Moiseev S. V. Microalbuminuria is a universal marker of poor prognosis. Clinical medicine. 2008; 11: 4-9.

[14] Konyukh E. A., Paramonova N. S. Clinical features of acute and chronic glomerulonephritis in children with endothelial dysfunction. Zhurnal GrGMU. 2010; 2: 149 (in Russ.). 
[15] Knight E. L., Verhave J. C., Spiegelman D., Hillege H. L., de Zeeuw D., Curhan G. C., de Jong P. E. Factors in fluencing serum cystatin $\mathrm{C}$ levels other than renal function and the impact on renal function measurement. Kidney Int. 2004; 65: 1416-1421.

[16] Lemieux C., Maliba R., Favier J., Théorêt J. F., Merhi Y., Sirois M. G. Angiopoietins can directly activate endothelial cells and neutrophils to promoteproinflammatory responses. Blood. 2005; 105 (4): 1523-1530.

[17] Stevens L. A., Schmid C. H., Greene T., Li L., Beck G. J., Joffe M. M., Froissart M., Kusek J. W., Zhang Y. L., Coresh J., Levey A. S. Factors other than glo-merularfiltration rate affect serum cystatin C levels. Kidney Int. 2009; 75: 652-660.

[18] Magee G. M., Bilous R. W., Cardwell C. R., Hunter S. J., Kee F., Fogarty D. G. Is hyperfiltration associated with the future risk of developing diabetic nephropathy? A metaanalysis. Diabetologia. 2009; 52: 691-697.

[19] Köttgen A., Selvin E., Stevens L. A., Levey A. S., Van Lente F., Coresh J. Serum cystatin C in the United States: the Third National Health and Nutrition Examination Survey (NHANES III). Am. J. Kidney Dis. 2008; 51: 385-394.

[20] Stam F., van Guldener C., Dekker J. M., Heine R. J., Bouter L.
M., Stehouwer C. D. Endothelial dysfunction contributes to renal function-associated cardiovascular mortality in a population with mild renal insufficiency: the Hoorn study. J. Am. Soc. Nephrol. 2006; 2: 537-545.

[21] Berezinets O. L., Rossolovskiy A. N., Blyumberg B. I. Modern aspects of future developments and the progression of coronary artery disease in patients with chronic kidney disease. Byulleten' meditsinskikh Internet-konferentsiy. 2014; 4 (1): $72-74$ (in Russ.).

[22] Landray M. J., Wheeler D. S., Newman D. J., Blann A. D., McGlynn F. J., Ball S., Townend J. N., Baigent C. Inflammation, Endothelial dysfunction and platelet activation in patients with chronic kidney disease: the chronic renal impairment in Birmingham (CRIB) Study. Am. J. Kidney Dis. 2004; 43: 244-253.

[23] Martens C. R., Edwards D. G. Peripheral Vascular Dysfunction in Chronic Kidney Disease. Cardiol. Res. Pract. 2011; 1: 2-6.

[24] Böger R. H., Lentz S. R., Bode-Böger S. M., Knapp H. R., Haynes W. G. Elevation of asymmetrical dimethylarginine may mediate endothelial dysfunction during experimental hyperhomocyst (e) inaemia in humans. Clin. Sci (Colch). 2001; 100 (2): 161-167. 